\title{
Evaluation of Vibration Analysis to Assess Bone Mineral Density in Children
}

\author{
HAJAR RAZAGHI ${ }^{1}$, REZA SAATCHI ${ }^{1}$, NICK. J. BISHOP ${ }^{2}$, \\ DEREK BURKE ${ }^{3}$, AMAKA C. OFFIAH ${ }^{2}$ \\ ${ }^{1}$ Industry and Innovation Research Institute, Sheffield Hallam University, Sheffield, S1 1WB, \\ UNITED KINGDOM \\ ${ }^{2}$ Department of Oncology \& Metabolism, Academic Unit of Child Health, University of Sheffield, Sheffield, \\ S10, 2TH, UNITED KINGDOM \\ ${ }^{3}$ Sheffield Children's Hospital, Sheffield, S10 2TH, \\ UNITED KINGDOM
}

\begin{abstract}
The effectiveness of vibration analysis to assess bone mineral density (BMD) in children with suspected reduction in bone density was studied. A system was designed that measured the ulna's vibration responses in vivo. The system was evaluated on the ulnae of 48 children (mean age $=12.0$, std=3.5 years), 31 of whom had been confirmed to have osteogenesis imperfecta (OI). All ch ildren had dual energy X-ray absorptiometry (DXA) scan as part of their routine clinical care and vibration analysis was performed on the same day. Frequency spectra of the ulnae's vibration responses were obtained and processed by principal component analysis. Four main principal components were selected and together with age, sex and right hand ulna's length were used in a regression analysis to estimate BMD. Regression analysis was repeated using the children's leave-one-out and partitioning methods. The percentage similarity and correlation between the DXA-derived and vibration analysis estimated BMDs using the leave-one-out were $80.34 \%$ and 0.59 and for partitioning were $74.2 \%$ and 0.64 respectively. There was correlation between vibration analysis BMD readings and those derived from DXA however a larger study will be needed to better establish the extent to which vibration analysis can assist in assessing bone density in clinical environments.
\end{abstract}

Keywords: Bone mineral density, Vibration analysis, Osteogenesis imperfecta

Received: April 20, 2019. Revised: February 26, 2020. Accepted: March 31, 2020. Published: April 22, 2020.

\section{Introduction}

The bones in a skeletal structure provide support, help with movement, protect vital internal organs and maintain mineral homeostasis and acid base balance. They are a reservoir of growth factors and cytokines and provide the environment for hematopoiesis within the marrow spaces [1]. Bone is a co mposite material that is made up of osteoblasts and osteocytes (for supporting cells), osteoclasts (for remodeling cells) and non-mineral matrix of co llagen and non-collagenous proteins called osteoid, with inorganic mineral salts d eposited within the matrix [2]. Assessing bone mineral density (BMD) in children is important for diagnosing and treating conditions that weaken its strength thus leading to frequent fractures. Bone mass gained during childhood and a dolescence is an important factor in influencing the risk of developing osteoporosis later in life. Peak bone mass, i.e. the amount of bony tissue accrued at the end of skeletal maturation [3], is dependent on several factors including genetic, weight-bearing physical activity, nutrition and hormonal status. A number of hereditary or acquired disorders may result in reduced bone density and thus increased bone fragility in children. Osteogenesis imperfecta (OI) is probably the commonest genetic ca use and refers to a gr oup of disorders associated with recurrent fractures, low bone mass and skeletal fragil ity [4-6]. Other causes of low bone mass in children include chronic inflammatory conditions (e.g. juvenile idiopathic arthritis, Crohn's disease), immobility (e.g. Duchenne muscular dystrophy, cerebral palsy) and drugs (e.g. steroids, antiepileptics).

Methods of assessing bone density include conventional radiographs, computed tomography (CT), quantitative CT (QCT), p eripheral quantitative CT (pQCT) and high-resolution peripheral quantitative CT (HRpQCT), magnetic resonance imaging (MRI), quantitative ultrasound (QUS), single X-ray absorptiometry (SXA) and dual X-ray absorptiometry/dual energy X-ray ab sorptiometry (DXA/DEXA) [7]. Medical imaging using magnetic resonance imaging (MRI) and CT are the most useful diagnostic modalities as th ey may provide further anatomical and pat hological/diagnostic information [8]. DXA is the most commonly used non-invasive technique to quantify bone mass (BM) and BMD [7,9]. It has however a number of limita tions when it is ap plied to growing individuals, as the major changes in skeletal size and $\mathrm{m}$ ass taking place with growth may result in incorrect interpretation of results $[9,10]$. Furthermore, although DXA is a relativ ely low exposure technique, children with suspected low bone mass often have repeated imaging, therefore a non-ionizing radiation technique, even as a screening tool would be beneficial in reducing the amount of 
radiation that these children are exposed to.

Vibration analysis is a well-established technique in industry for analyzing physical structural properties of materials including their densities. There were a number of encouraging reports of vi bration analysis to assess bone integrity [11-19]. These were mainly in vitro on adults, but our study has been conducted in children in vivo and the vibration analysis and DXA derived BMD results have been compared.

\section{Methodology}

In this section the procedures to recruit the patients, the manner their bone vibration signals were recorded and processed are explained.

\subsection{Recruitment}

This was a prospective observational study conducted between August 2016 and August 2017. Ethical approval for the study was obtained from the National Health Service (UK) Ethics Committee. Forty eight children and young people aged between 5 and 18 years (mean 12 years, standard deviation 3.5 years), attending the Radiology Department of a single pediatric tertiary referral center for a DXA scan to assess bone density were prospectively consented and recruited. Their relevant clinical and demographic details are summarized in Table 1.

Table 1 Summary of participants' clinical and demographic details

\begin{tabular}{|c|c|c|}
\hline Variable & Parameters & Values \\
\hline $\begin{array}{l}\text { Age } \\
\text { (years) }\end{array}$ & $\begin{array}{l}\text { Mean (SD) } \\
\text { Median } \\
\text { Minimum } \\
\text { Maximum } \\
\text { Range }\end{array}$ & $\begin{array}{l}12.0(3.5) \\
11.9 \\
5.8 \\
17.3 \\
11.5\end{array}$ \\
\hline Sex & $\begin{array}{l}\text { Male }(\%) \\
\text { Female }(\%)\end{array}$ & $\begin{array}{l}24(50 \%) \\
24(50 \%)\end{array}$ \\
\hline $\begin{array}{l}\text { Whole body BMD } \\
\left(\mathrm{g} / \mathrm{cm}^{2}\right)\end{array}$ & $\begin{array}{l}\text { Mean (SD) } \\
\text { Median } \\
\text { Minimum } \\
\text { Maximum } \\
\text { Range }\end{array}$ & $\begin{array}{l}0.69(0.16) \\
0.68 \\
0.44 \\
1.05 \\
0.61\end{array}$ \\
\hline Weight (kg) & $\begin{array}{l}\text { Mean (SD) } \\
\text { Median } \\
\text { Minimum } \\
\text { Maximum } \\
\text { Range }\end{array}$ & $\begin{array}{l}41.3(19.5) \\
35.9 \\
15.1 \\
120.1 \\
105.0\end{array}$ \\
\hline Height $(\mathrm{cm})$ & $\begin{array}{l}\text { Mean (SD) } \\
\text { Median } \\
\text { Minimum } \\
\text { Maximum } \\
\text { Range }\end{array}$ & $\begin{array}{l}141.6(18.4) \\
144.0 \\
90.0 \\
175.4 \\
85.4\end{array}$ \\
\hline $\begin{array}{l}\text { Right hand } \\
\text { ulna length }(\mathrm{cm})\end{array}$ & $\begin{array}{l}\text { Mean (SD) } \\
\text { Median } \\
\text { Minimum } \\
\text { Maximum } \\
\text { Range }\end{array}$ & $\begin{array}{l}21.5(3,3) \\
21.5 \\
15.5 \\
28 \\
12.5\end{array}$ \\
\hline $\begin{array}{l}\text { Confirmed } \\
\text { medical diagnosis }\end{array}$ & $\begin{array}{l}\text { None } \\
\text { Osteogenesis } \\
\text { imperfecta } \\
\text { others }\end{array}$ & $\begin{array}{l}2 \\
31 \\
15\end{array}$ \\
\hline
\end{tabular}

DXA scans were performed by radiographers within the hospital's Radiology Department using a fan-beam GE Lunar iDXA d ensitometer and fo llowing the standard protocols [20]. All DXA scans were clinically indicated and none were performed solely for the purposes of this study. Following their DXA scan, the recruited children and their parents/guardians completed the vibration test assent or consent forms (depending on their age) prior to the children having the bone vibration test. Vibration analysis was conducted on all children by a single individual on the same day as the DXA scan.

\subsection{Bone vibration recording system and its set up}

The ulna was chosen for bone density assessment because of its relative ease for both inducing and measuring vibration. The olecranon was avoided as it is a more sensitive part of the ulna. Vibration was induced by tapping the ulna two centimetres away from the olecranon. The vibration response was recorded from the head of the ulna at the point where the ulna is most prominent (closest to the skin surface). The vibration tests were performed using a computer controlled system shown in Fig. 1. It consisted of: (i) a bone vibration inducing device (called a tapper), (ii) a circuit driver for the tapper, (iii) a vibration response sensor, (iv) a signal conditioning (amplification and filtering) device, (v) an a nalogue to digital convertor (called myDAQ(C) and (vi) a computer for the graphic user interface, storage and analysis facilities. The individual parts are described in the next sections.

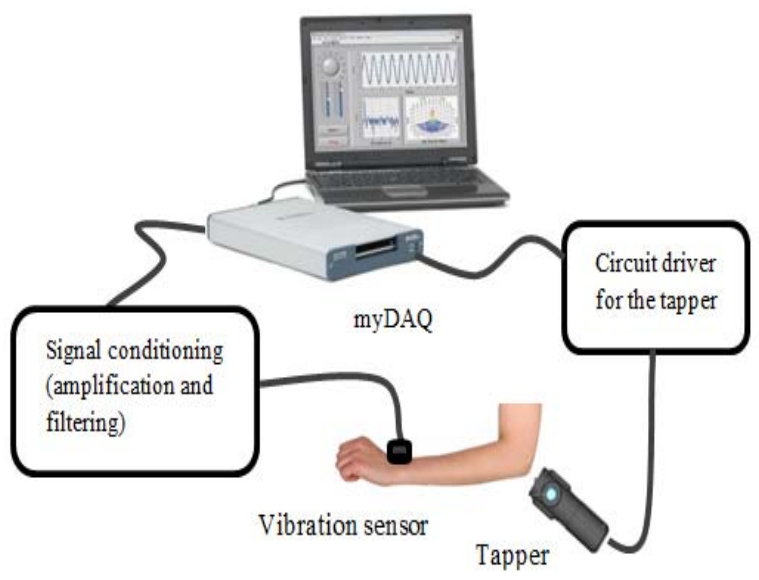

Fig. 1 Bone vibration response recording system

\subsection{Bone vibration inducing system}

A small computer controlled device (called a tapper) was designed to induce bone vibration in vivo. The de vice has an embedded moving steel shaft that moves forward and then returns to its rest position. To activate the tapper, a square pulse was sent from the computer through the National Instrument ${ }^{\odot}$ data acquisition device $\left(m y D A Q^{\odot}\right)$ to a power transistor acting as an interface to the tapper. The transistor ensured sufficient current to drive the device. The device was placed gently on the required test site (two centimetres from the olecranon) and the shaft of the tapper 
mildly tapped the s kin surface above the bone with a controlled force, inducing the required bone vibration. The force magnitude and duration were controlled by varying the magnitude and duration of the supply voltage to the device. A user interface based on the National Instrument's LabView $^{\odot}$ fully controlled the tapper's operation. The tapper's supply voltage was 10 volts and each tap lasted for $50 \mathrm{~ms}$. The exerted force and the duration of each tap were adjusted through the graphic user interface developed in the National Instrument's LabView ${ }^{\odot}$. For each ch ild, 10 bone vibration responses were recorded each separated by one second. Prior to using the device on children, its operation was tested on healthy adult volunteers and its parameters (magnitude of the force and duration of each tap) were established in such a way as to provide a sufficiently large vibration response signal without causing discomfort. At the start of each recording, the children were informed that they could immediately stop the recording if th ey felt uncomfortable, but none of the children indicated they felt any discomfort.

The induced bone vibration responses were detected using a $\mathrm{C} M-01 \mathrm{~B}^{\odot}$ vibration sensor [21] that was fully encapsulated in a customized plastic casing to e nsure electrical safety for the purpose of this study. The sensor is a contact microphone device that uses sensitive but robust PVDF piezoelectric film combined with a low-nois e electronic preamplifier for vibration detection. Its sensitivity is 40 volts $/ \mathrm{mm}$ with flat frequency response in the range of 8 $\mathrm{Hz}$ to $2 \mathrm{kHz}$. Its electronic noise is $1 \mathrm{mV}$ (peak-to-peak). We did not use inertia measurement units (e.g. accelerometer and gyroscope) for vibration detection as these could detect hand movements, a recognized problem for in vivo studies, especially those involving children. The used sensor's advantage was that it did not pick up body movements. The sensor was fixed on the skin above the ulnar head using Mefix(C self-adhesive fabric.

The vibration signal was amplified by a factor of 6 and then lowpass filtered using a $4^{\text {th }}$ order Butterworth filter with a cut-off frequency set to $2 \mathrm{kHz}$. The cut-off frequency was the bandwidth limit of the vibration sensor. The signal was then digitized using the National Instrument's myDAQ ${ }^{\circ}$ data acquisition device. The sample rate was 100,000 samples per second (the limit of myDAQ). The myDAQ was connected to a la ptop computer using a USB cable that displayed the bone vibration responses in real-time and stored them for off-line processing.

The graphic user interface was developed using the National Instrument's LabView ${ }^{\odot}$ software. It e nabled real time display of signals, allowed the user to adjust the amplitude and width of the square pulse that activated the tapper thus controlling the tapping force, the duration of each tap, time between successive taps and sample rate.

\subsection{Bone vibration recording procedure}

The vibration signals were recorded with the patient sitting on a ch air of adjustable height with their right hand resting on a suitably located soft mat on a table. The vibration was induced by gently holding the tapper on the skin, $2 \mathrm{~cm}$ from the olecranon. T he computer then facilitated the sending of 10 pulses to the tapper, recording 10 successive vibration responses separated by 1 second. Following the vibration test, th e child was asked for feedback regarding the comfort of vibration compared with DXA by completing a non-validated questionnaire.

\subsection{Bone vibration processing procedure}

The steps to process the vibrations signals are explained in the following sections.

Feature extraction and selection: The vibration signals each consisting of 10 vibration responses had their mean removed and were discrete Fourier transformed prior to obtaining their magnitude spectra. The magnitudes of the peaks in the frequency magnitude spectra declined sharply at around 300 $\mathrm{Hz}$. There were 20 peaks up to $300 \mathrm{~Hz}$ and these magnitudes were chosen as features for analysis. These gave sufficient spectral information without producing an excessive number of variables. The resulting magnitudes were normalized by initially dividing them by the value of the largest peak (this ensured a maximum magnitude of 1 , with all others values in relation to 1) and then they were divided by their standard deviations. This normalization ensured that spectral features across the children could be better compared. The 20 selected normalized magnitudes were processed by principal component analysis (PCA) and a sc ree plot of the Eigen values was obtained. This indicated that the four main principal components represented $90.2 \%$ of the overall variance. Therefore the vibration signal for each chil $\mathrm{d}$ was represented by four main principal components. Age and sex can influence BMD values and ulna (right ulna's length was measured for all ch ildren) length $(u)$ could affect the acquired vibration responses, these three parameters were also included in the feature matrix, thus providing seven features in total (in th is matrix females and males were represented numerically by 0 and 1 respectively).

Estimating BMD using vibration analysis: Linear regression was used to model the bone vibration information as indicated by

$$
\left[\begin{array}{ccccccc}
p c_{11} & p c_{12} & p c_{13} & p c_{14} & u_{1} & \text { age }_{1} & \text { sex }_{1} \\
p c_{21} & p c_{22} & p c_{23} & p c_{24} & u_{2} & \text { age }_{2} & \operatorname{sex}_{2} \\
& & \cdot & & \\
& \cdot & & \\
p c_{n 1} & p c_{n 2} & p c_{n 3} & p c_{n 4} & u_{n} & \text { age }_{n} & \operatorname{sex}_{n}
\end{array}\right]\left[\begin{array}{l}
c_{1} \\
c_{2} \\
\cdot \\
\cdot \\
c_{7}
\end{array}\right]=\left[\begin{array}{c}
B M D_{1} \\
B M D_{2} \\
\cdot \\
\cdot \\
B M D_{n}
\end{array}\right]
$$

where $n$ is the number of children, $p c_{i k}$ is the $k^{\text {th }}$ principal component for child $i(i=1 \ldots n), a g e_{i}$ and $\operatorname{sex}_{i}$ are age and sex for child $i, c_{1} \ldots c_{7}$ are the regression coefficients and $B M D_{i}$ is the DXA derived BMD for $i^{\text {th }}$ child. The regression modelling required the coefficients $c_{1} \ldots c_{7}$ to be determined. As the data set was not large, two approaches were followed for comparison. In the first method, referred to in this paper as, "leave-one-out", the feature matrix (on the left hand side of equation (1)) and the BMD matrix (on the right hand side equation (1)) indicating DXA derived BMD values for all but one child were fo rmed. Using the two matrices, the regression coefficients were determined. The coefficients were then multiplied with the feature matrix of the excluded child, i.e.

[ $p c_{\text {lexcluded }} p c_{\text {2excluded }} p c_{3 \text { excluded } 3} p c_{\text {4excluded }} u_{\text {excluded }}$ age $e_{\text {excluded }}$ sex $\left.x_{\text {excluded }}\right]$ to estimate the vibration analysis derived BMD. The excluded child was returned to the matrices and the process was repeated for all c hildren. For the second regression 
modelling method, referred to in this paper as the "partition method", the feature matrix and DXA derived BMD matrix were formed for all 48 children and then arranged in ascending order of BMD valu es. The children in the odd rows of the matrices we re used to determine the regression coefficients. The coefficients were then applied to the children in the ev en rows of the matrices to estimate vibration analysis BMD v alues for tho se children. The sorting operation ensured roughly equal distribution of BMD values in determining the regression coefficients and in evaluating the method. The vibration derived BMD values estimated using regression analysis were compared with those derived from DXA.

\section{Results}

The distribution of whole-body BMD values provided by DXA for the children included in the study is shown in Fig. 2. The largest proportion of BMD values was at $0.6 \mathrm{~g} / \mathrm{cm}^{2}$. Although density is conventionally measured as mass per volume with the $\mathrm{u}$ nit of $\mathrm{g} / \mathrm{cm}^{3}$, DXA derived BMD is represented as mass per unit area, i.e. $\mathrm{g} / \mathrm{cm}^{2}$, and so the unit of $\mathrm{g} / \mathrm{cm}^{2}$ is used for BMD representation throughout this paper.

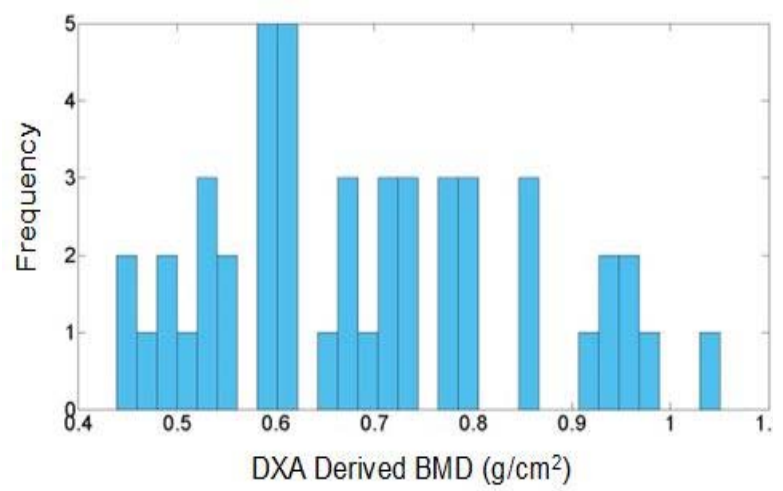

Fig. 2 Distribution of DXA derived BMD values for children included in the study.

Fig. 3 shows a typical vibration response for the ulna. Its oscillation lasts ab out $70 \mathrm{~ms}$. The amplitude of the response is initially relatively large but decays very rapidly. The initial response has a narrow width (higher frequency) with duration about $5 \mathrm{~ms}$.

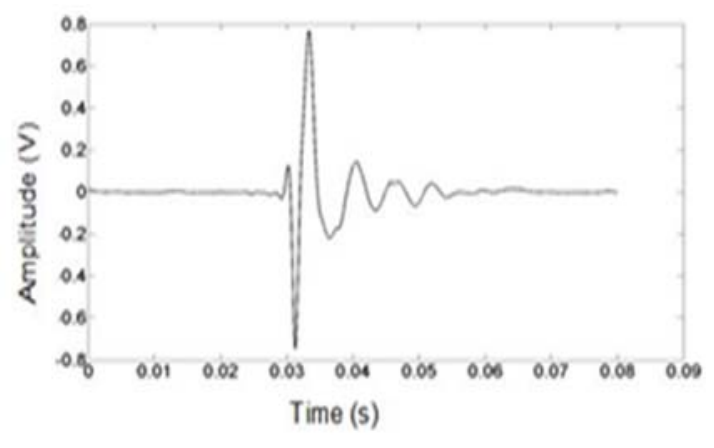

Fig. 3 A typical vibration response recorded from an ulna.

Given that the vibration was both induced in and recorded from the ulna through skin, (and potentially fat and muscle), a key concern was the extent to which these soft tissues as well as the device inducing the vibration and the vibration sensor would alter the recorded vibration responses. As the recordings were performed in vivo on children, detailed exploration of these factors was not practical in this study. However, we have previously explored these issues in vitro using turkey legs [22, 23]. In these studies, vibration responses were recorded from intact turkey legs (i.e. with all s oft tissues left in place) a nd then the experiment was rep eated with the bones completely stripped of all soft tissues. Our results indicated that although soft tissue alters the recorded vibration response's shape and oscillation frequency, the vibration response recorded from the skin surface still corre lated with that recorded directly from the bone's surface. In this current study, vibration was induced and vibration response recorded very close to the ulna (through a few millimetres of skin thickness) in an attempt to minimize the damping effect of soft tissues.

Fig. 4 shows the vibration response magnitude frequency spectrum recorded from a chi ld's ulna. The magnitude frequency spectra of the recorded vibration responses showed some variations from child to child with regards to the shape, magnitude and frequency range, but their main frequency components were below $300 \mathrm{~Hz}$.

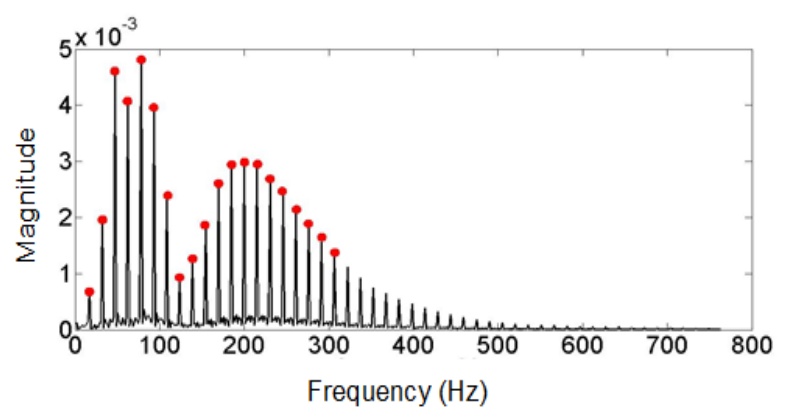

Fig. 4 Magnitude frequency spectrum of an ulna's vibration response.

Fig. 5 shows the scree plot of the Eigen values of the principal components used to decide on number of components for regression analysis. The first four principal components were chosen as they amounted to $90.2 \%$ of overall Eigen value (latent).

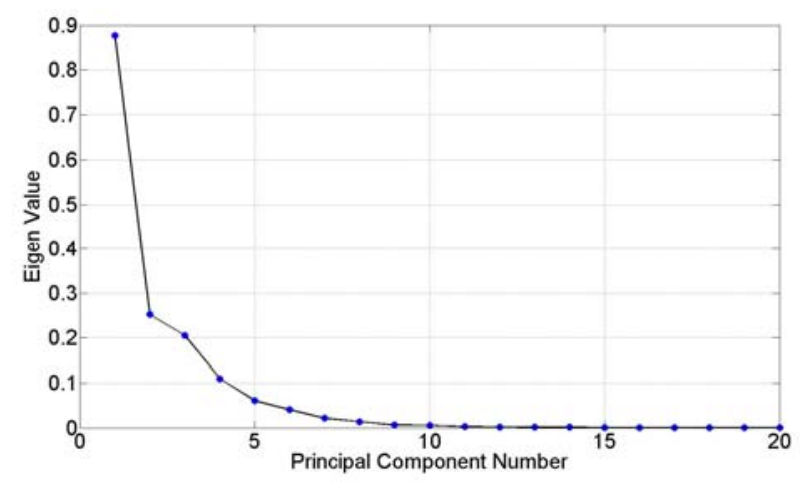

Fig.5 The scree plot of the principal components. 
Figs. $6 \mathrm{a}$ and $\mathrm{b}$ show the relationship between the DXA derived BMD values and the BMD values estimated using vibration analysis using leave-one-out and partition methods respectively. Figure $6 \mathrm{a}$ includes all children but Figure $6 \mathrm{~b}$ contains the 24 children included in the evaluation matrix of the regression model. The figures indicate that there is a re lationship between the DXA derived and vibration analysis estimated BMD values, although there are significant deviations between the two measures for some children.

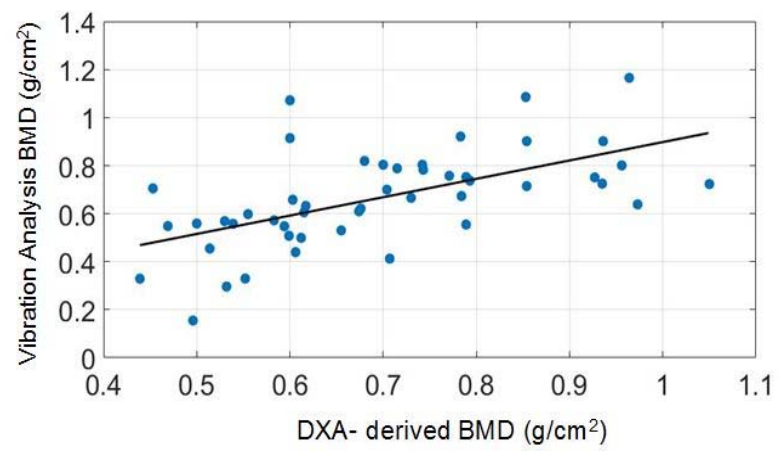

(a)

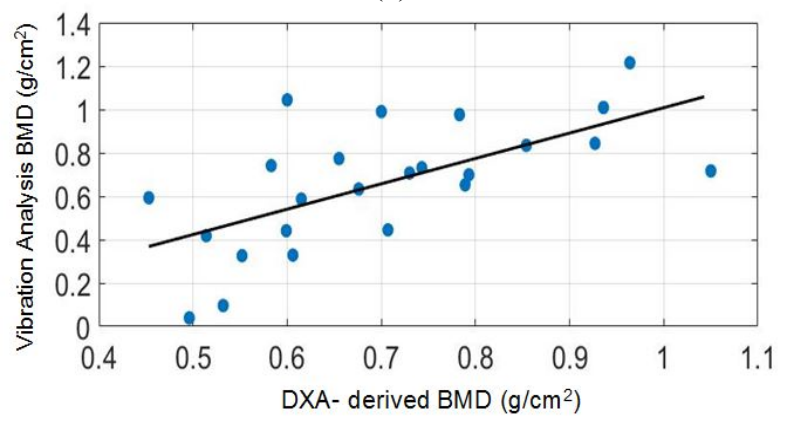

(b)

Fig. 6 Correlation between DXA derived and vibration analysis estimated BMDs (a) leave-one-out method and (b) partition method.

Figs. 7a and $\mathrm{b}$ show bar charts for DXA derived and vibration analysis estimated BMD values using the leaveone-out and partition methods. The BMD differences between the DXA and vibration analysis are shown in Fig. 8.

Some children had significantly larger deviation between their DXA derived and vibration analysis estimated $\mathrm{BMD}$ values. This issue was further explored by considering the cases that had at least $30 \%$ deviation. The associated children were $2,4,8,10,15,16,28,37,39,47$ and 48 (the child numbers associate with Figure 7a). The related information such as medication, previous history of bone fractures, height, weight and body mass index (BMI) for these 11 children were co mpared against the remaining 37 children. Amongst these, the BMI for the 11 children showed a noticeable differ ence compared to ot her 37 children. The analysis results are summarized in Table 2. The BMI for the 11 children was $23.87 \mathrm{~kg} / \mathrm{m}^{2}$ while the other 37 children this was $18.5 \mathrm{~kg} / \mathrm{m}^{2}$. BMI represents the weight $(\mathrm{kg}) /$ height $^{2}\left(\mathrm{~m}^{2}\right)$. A BMI of $25.0 \mathrm{~kg} / \mathrm{m}^{2}$ or higher is overweight while 18.5 to $24.9 \mathrm{~kg} / \mathrm{m}^{2}$ is not overweight. This analysis results may suggest that the vibration analysis method may be less accurate in children with a higher BMI.
This may be due to a larger damping effect of soft tissues on recorded bone vibration responses.

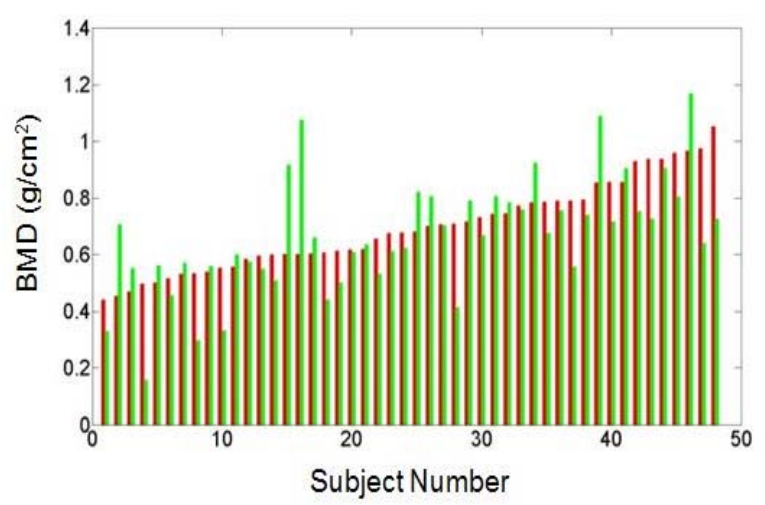

(a)

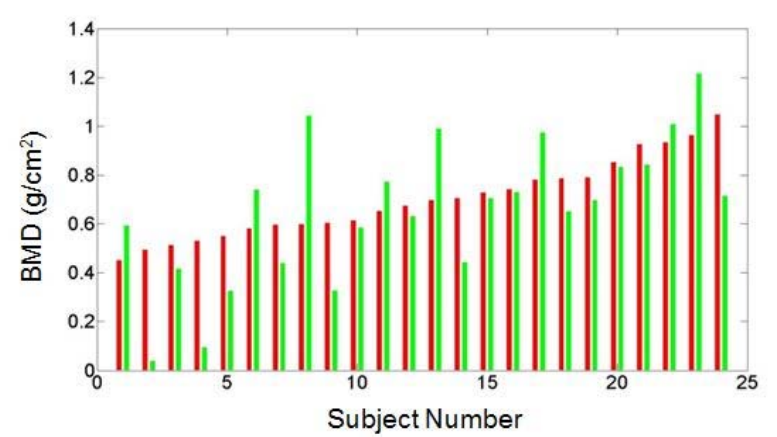

(b)

Fig. 7 BMD bar chart for (a) leave-one-out method, (b) partition method. Red: DXA derived, Green vibration analysis estimated.

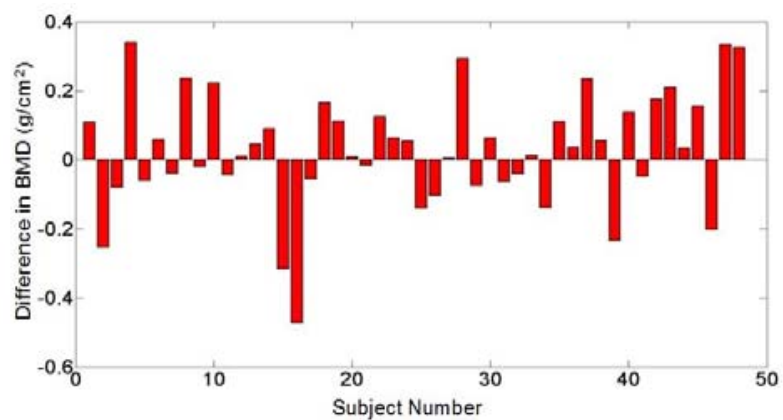

(a)

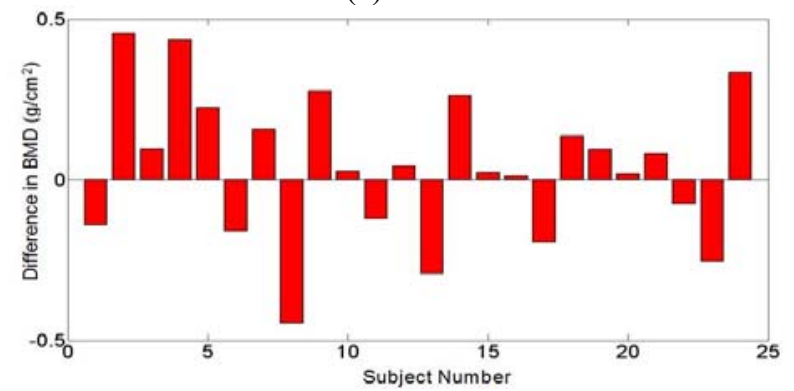

(b)

Fig. 8 Differences between the DXA derived and vibration analysis estimated BMD, (a) leave-one-out method, (b) partition method. 
Table 2 Body mass index (BMI) analysis

\begin{tabular}{cccc}
\hline \hline Children & $\begin{array}{c}\text { Weight } \\
\text { average } \\
\text { (standard } \\
\text { deviation) } \\
(\mathrm{kg})\end{array}$ & $\begin{array}{c}\text { Height } \\
\text { average } \\
\text { (standard } \\
\text { deviation) } \\
(\mathrm{m})\end{array}$ & $\begin{array}{c}\text { BMI } \\
\text { average } \\
\text { (standard } \\
\text { deviation) } \\
\left(\mathrm{kg} / \mathrm{m}^{2}\right)\end{array}$ \\
\hline $2,4,8,10,15,16,28$, & 48.95 & 1.38 & 23.87 \\
$37,39,47$ and 48 & $(30.34)$ & $(0.21)$ & $(9.77)$ \\
(subject numbers are & & & \\
as those in Fig.7a) & & & \\
& & 1.43 & 18.50 \\
Remaining 37 children & 39.09 & $(0.18)$ & $(3.95)$
\end{tabular}

Box plots of DX A derived and vibration analysis estimated BMD values for leave-one-out and partition regression analysis methods are shown in Figs. 9a and $b$. The vibration analysis estim ated BMD values have a broader distribution than DXA derived BMD values but their medians are close.

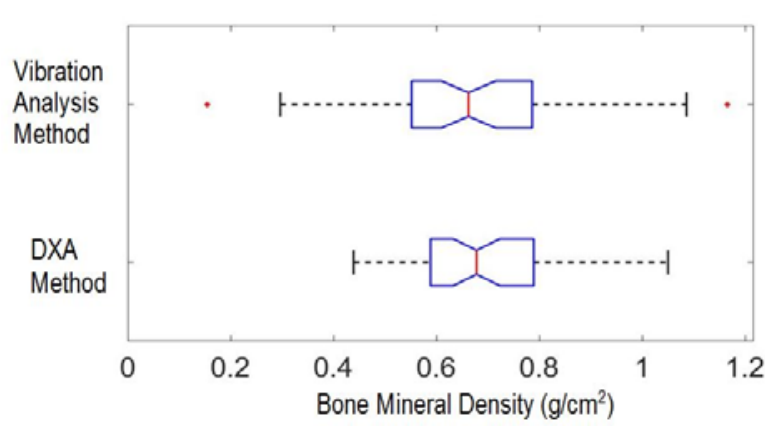

(a)

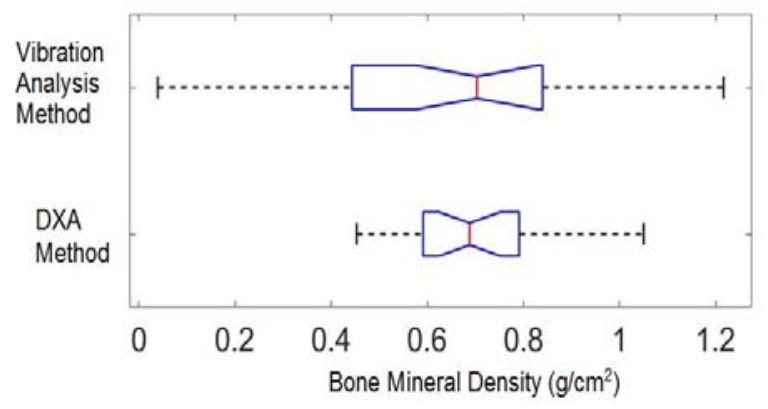

(b)

Fig. 9 Box plots of BMD values obtained using (a) leaveone-out method, (b) partition method.

In order to allow clinicians to compare two different measurement techniques, an analysis based on the BlandAltman statistical method was used [24]. The analysis is based on a scatter plot of the difference of two techniques against their averages. The Bland-Altman plot for the DXA derived and vibration analysis estimated methods using leave-one-out method is shown in Fig. 10(a) and for the partition method in Fig. 10(b). The plots indicate the bias, i.e. average difference. This should ideally be zero. They also indicate the limits of agreement, i.e. a range that s pans BMD difference from mean-1.96 $\times$ standard deviation to mean $+1.96 \times$ standard deviation. This range represents $95 \%$ of comparison points. For the leave-one-out method the limits of agreement were from -0.3 to $0.36 \mathrm{~g} / \mathrm{cm}^{2}$ and for the partition method the limits were from -0.4 to $+0.49 \mathrm{~g} / \mathrm{cm}^{2}$.
The majority of points within the scatter plots fell within \pm 2SD and are therefore clinically acceptable.

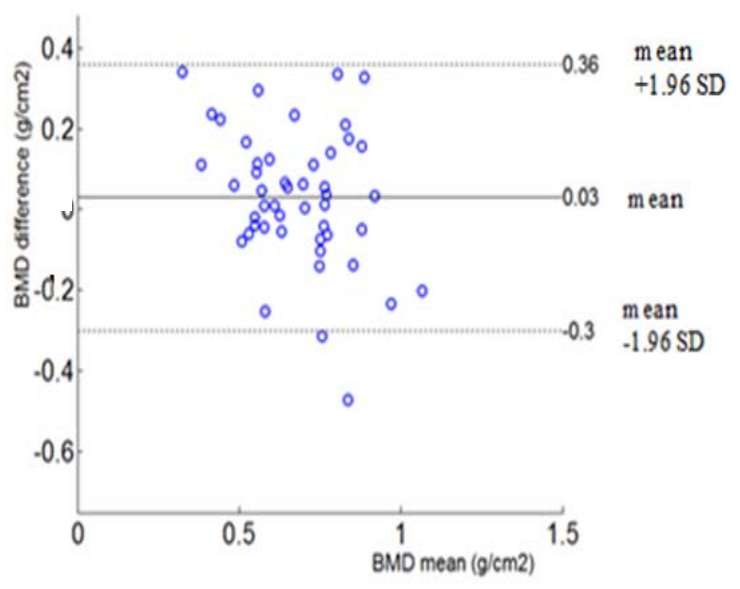

(a)

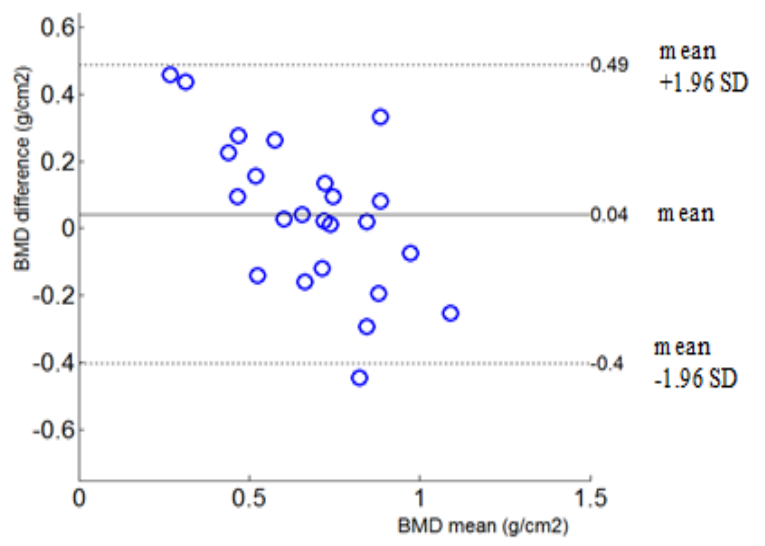

(b)

Fig. 10 Bland-Atman plot for (a) leave-one out and (b) partition methods.

Table 3 compares the vibration analysis estimated BMD values for both leave-one out and partition methods against the DXA derived BMD values.

Table 3 Comparison of BMD $\left(\mathrm{g} / \mathrm{cm}^{2}\right)$ values obtained from DXA with those estimated from vibration analysis (VA) for the leave-one-out and partition methods.

\begin{tabular}{lcccc}
\hline \hline & \multicolumn{2}{l}{ Leave-One-Out } & \multicolumn{2}{c}{ Partition } \\
\hline \hline Statistics & DXA & VA & DXA & VA \\
\hline Minimum & 0.44 & 0.16 & 0.45 & 0.04 \\
Maximum & 1.05 & 1.17 & 1.05 & 1.22 \\
Range & 0.61 & 1.01 & 0.60 & 1.18 \\
Mean & 0.69 & 0.66 & 0.70 & 0.66 \\
Standard- & 0.16 & 0.20 & 0.16 & 0.29 \\
deviation & & & & \\
$\quad \begin{array}{l}\text { Median } \\
\text { Interquartile- }\end{array}$ & 0.68 & 0.66 & 0.69 & 0.70 \\
range & 0.20 & 0.23 & 0.20 & 0.40 \\
& & & &
\end{tabular}

The mean BMD val ues for both leave-one-out and partition methods (vibration analysis) differ from the mean 
DXA derived BMD values by $4.35 \%$ and $5.71 \%$ respectively. The respective medians differ by $2.94 \%$ and $1.45 \%$. Therefore the vibration analysis and DXA give close mean and $\mathrm{m}$ edian values for $\mathrm{BMD}$. The $\mathrm{BMD}$ range (maximum - minimum BMD values), standard deviation and interquartile range for vibration analysis are larg er than those for DXA derived values. The standard deviation of BMD values for the lea ve-one-out and partition m ethods (vibration analysis) differ from the stan dard deviation of DXA derived BMD values by $-25.00 \%$ and $-81.25 \%$ respectively. The 11 children with much larger BMI could be causing the large differences in the range and standard deviation.

Summary statistics com paring DXA derived and vibration analysis estimated BMD values for the leave-oneout and partition regression analysis methods are provided in Table 4.

Table 4 Summary statistical comparison of the methods for determining BMD

\begin{tabular}{llc}
\hline \hline Method & $\begin{array}{c}\text { Correlation } \\
\text { coefficient }\end{array}$ & $\begin{array}{c}\text { Percentage } \\
\text { similarity }\end{array}$ \\
\hline Leave-one-Out & 0.59 & 80.34 \\
Partition & 0.64 & 74.20
\end{tabular}

The correlation c oefficients between the DXA derived and vibration analysis estimated BMD values for the leave-one-out and partition methods were 0.59 a nd 0.64 respectively. The percentage similarity ( $p s$ ) (indicated in Table 4) were also calculated using

$$
p s=\left(1-\sum_{i=1}^{n}\left(\frac{\text { absolute }\left(d_{i}-v_{i}\right)}{d_{i}}\right)\right) \times 100
$$

where $n$ is the number of children ( $n=48$ for leave-one-out and 24 for partition method) and $d_{i}$ and $v_{i}$ are DXA derived and vibration analysis estimated BMD values for child $i$.

The value for $p s$ indicates average similarity between the DXA derived and vibration analysis estimated BMD values. The $p s$ values for the leave-one out and partition methods were $80.34 \%$ and $74.20 \%$ respectively.

\section{Discussion}

The study indicates that vibration analysis may have potential to be a harmless, non-invasive, cost effective and easy to apply $\mathrm{m}$ ethod for estimating BMD. However a number of issues need to be further studied before vibration analysis can be used as a routine BMD assessment method in the clinical environment. These include:

- The number of children included in the study was small. This could have reduced the accuracy of the vibration analysis method in determining BMD when using the regression model. The BMD val ues estimated using vibration analysis relied on regression modelling. An increase in the number of children can provide a more representative range of $\mathrm{BMD}$ values and thus could improve its performance.

- Partitioning and lea ve-one-out methods were compared in setting up the regression models. In bo th models,
DXA derived values were used as reference. The DXA derived values may have inaccuracies as discussed in the introduction of the paper. It would be advantageous to calibrate the regression models against other imaging modalities particularly High-Resolution Peripheral Computed Tomography (HRpQCT). However there is a cost implication for re search for the scans as well as ethical issues related subjecting children to the scans for the purpose of research. We are currently synthesising bones with varied densities and will test $t$ he vibration analysis on these artificial bones.

- The instrumentation system used in the study to record the vibration responses is currently a prototype and its operation can be further improved. The current device is hand held and the manner in which it was held in relation to the recording site for each patient may have affected the resulting responses. In th is study all vibration responses were recorded by a sin gle experienced operator thus reducing this effect. She initially practiced the device on adult volunteers to obtain best operating performance. We are currently building a new version of the device that can make the device operator independent.

- The analysis was performed only on the ulna. We will in future repeat the tests on other long bones such as the tibia and fibula to ascertain the degree to wh ich their vibration derived BMD measurements correlate with those obtained from the ulna.

- The effects of soft tissue, muscle and joints on the recorded vibration responses were no $t$ incorporated in the analysis. Modelling could be made more sophisticated by incorporating these effects.

- The study indicated that the vibration analysis may not be as effective in children with high BMI. Th is issue needs a more detailed investigation with a larger number of children.

- The effects of medication and previous history of ulna fractures on results were not explored in this study (due to small sample size) and thus can be explored further.

The vibration analysis method is not designed to be a replacement for DXA or any other modality for BM D assessment but rather it is aimed to be a cost effective, easy to use, non-invasive and completely harmless technology for screening purposes. Our study supports previous related studies indicating the potential of vibration analysis in assessing bone density. As DXA and other modalities for assessing $\mathrm{BMD}$ are $\mathrm{e}$ xpensive and re quire access $\mathrm{t} o$ specialized medical experti se and centres, the vibration analysis approach may allow medical practitioners to have a practical tool for a quick screening of those suspected of abnormal bone density, resulting in an increased likelihood of earlier detection of osteoporosis and its medical treatment resulting in a reduction in bone fractures. Furthermore, the tool may allow the BMD im provement resulting from medications to be monitored more regularly as it is a harmless and cost-effective tool.

\section{Conclusion}

An in vivo evaluation of vibration analysis to estimate bone mineral density (BMD) in 48 children with suspected low bone mass including some with known 
osteogenesis imperfecta (OI) was carried out. T wo regression models were set up based on data partitioning and leave-one-out approaches. DXA derived BMD values were used as reference. The DXA derived and vibration analysis estimated BMD values correlated, indicating that vibration analysis may be valuable in assessi ng BMD. We are currently further developing both the instrumentation and data processing of the bone vibration analysis method to improve its accuracy and reliability.

\section{Acknowledgement}

The authors are very grateful to all the children who kindly took part in the study and their parents for giving their assent/consent. They also appreciate Dr Paul Arundel (Consultant at Sheffield Children's Hospital, UK) for very kindly helping with the recruitment of the children included in the study.

\section{References}

[1] Clarke, B (2008) Normal bone anatomy and physiology, Clin J Am Soc Nephrol. 3(suppl 3):S131-S139.

[2] Kini, U, Nandeesh, BN (2012) Physiology of b one formation, remodeling, and metabolism, in I. Fogelman et al. (eds.), Radionuclide and $\mathrm{H}$ ybrid Bone Imaging, Springer-Verlag Berlin Heidelberg, 29-57.

[3] Bonjour, J-Ph., Theintz, G, Law, F, Slosman, D, Rizzoli, R (1994) Peak bone mass, Osteoporosis International, 4(suppl 1):S7-S13.

[4] Cundy, T (201 2) Recent advances in osteogenesis imperfecta, Calcif Tissue Int, 90:439-449.

[5] Bishop, N (2016) Bone material properties in osteogenesis imperfecta, Journal of Bone and Mineral Research, 31(4):699-708.

[6] Arundel, P, Bishop, N (2009) Diagnosing osteogenesis imperfecta, Paediatrics and Child Health, Elsevier Ltd, 20 (5): 225-231.

[7] Ramos, RML, Armán, JA, Galeano, NA, Hernández, AM, Gómez, JMG., Molinero, JG (2012) Dual energy X-ray absorptiometry: Fundamentals, methodology, and clinical applications, Radiología, 54(5):410-423.

[8] Lubicky, JP (2012) The spine in osteogenesis imperfecta, Spine Deformity (Spine Deformity Preview Issue), 124-132.

[9] Mäyränpää, MK, Helenius, I, Valta, H, Mäyränpää, MI, Toiviainen-Salo, S, and Mäkitie, O (200 7) Bone densitometry in the diagnosis of vertebral fractures in children: Accuracy of ve rtebral fracture assessment, Bone, 21:353-359.

[10] Schönau, E (1998) Problems of bone analysis in childhood and ado lescence, Pediatr Nephrol, 12:420429.

[11] Nokes, L, Fo irclought, JA, Mintowt-Czyz, WJ, Mackies, I, William s, J (1984) Vibration analysis of human tibia: the effect of soft tissue on the output from skin mounted accelerometers, J. Biomed Eng., 6:223226.

[12] Nokes, L, Mintowt-Czyz, WJ, Fairclought, JA, Mackies, I, Williams, J (1985) Vibration analysis in the assessment of conservatively managed tibial fractures, J. Biomed Eng., 7:40-44.
[13] Nokes, L (1999) The use of low-frequency vibration measurement in orthopaedics, Proc Instn Mech Engrs, 213 (part H).

[14] Van Der Perre, G, Lowet, G (1996) In viva assessment of bone mechanical properties by vibration analysis and ultrasonic wave propagation analysis', Bone, 18(1): 29S-35S.

[15] Bediz, B, Ozguven, HN, Korkusuz, F (2010) Vibration measurements predict the mechanical properties of human tibia, Clinical Biomechanics, 25:365-371.

[16] Nikiforidis, G, Bezerianos, A, Di marogonas, A, Surherland, C (1990) Monitoring of fracture healing by lateral and axial vibration analysis, J. of Biomechanics, 23(4):323-330.

[17] Roberts, SC, Hutchinson, TM, Arnaud, SB, Kiratli, BJ, Martins, RB, Steele, C R (1996) Noninvasive determination of bone mechanical properties using vibration response: a re fined model and validation in vivo, J. Biomechanics, 29 (1): 91-98.

[18] Cornelissen, M, Corn elissen, P, V, Der Perre, G, Christensen, AB, Ammitzboll, F, Dyrbye, C (1987) Assessment of tibial stiffness by vibration testing in situ-iii. Sensitivity of different modes and interpretation of vibration measurements, J. Biomechanics, 20 (4): 333-342.

[19] Wong, LCY, Chiu, WK, Russ, M, Liew, S (2012) Review of techniques for monitoring the healing fracture of bon es for implementation in an internally fixated pelvis, Medical Engineering \& Physics, 34: 140-152.

[20] Lentle, BC, Brown, JP, Khan, A, Leslie, WD, Levesque, J, Lyons, DJ, Siminoski, K, Tarulli, G, Josse, R.G, Hosman, A (2007) Scientific Advisory Council of Osteogenesis Canada and Canadian Association of radiologists, Recognising and reporting vertebral fractures: reducing the risk of future osteoprotic fractures', Can. Assoc Radiol J., 58 (1):27-36.

[21] CM-01B, http://www.mouser.com/ds/2/418/Contact_Microphone769347.pdf, last accessed 06/07/2017.

[22] Razaghi, H, Saatchi, R, Offiah, A, Bishop, N, Burke, D (2012) Spectral analysis of bone low frequency vibration signals, 8th IEEE, IET International symposium on Communication Systems, Networks and Digital Signal Processing, July 18-20 2012, Poznan, Poland.

[23] Razghi, H, Saatchi, R, Burke, D, Offiah, A (2014) An investigation of relationship between bone vibration frequency and its mass-volume ratio, IEEE International Conference on Acoustics, Speech, and Si gnal processing (ICASSP), May 4-9 2014, Florence, Italy.

[24] Bland, JM, Altman, DG (1986) Statistical method for assessing agreement between two m ethods of clinical measurement, The Lancet. Feb 8;1(8476):307-10.

Hajar Razaghi $(\mathrm{PhD})$ is a lecturer at Sheffield Hallam University with research interest in medical electronics.

Reza Saatchi (PhD, CEng, MIET, FHEA) is a professor of electronics (Medical Engi neering) at Sheffield Hallam 
University. His research interest is primarily medical electronics.

Nick Bishop is a professor of Paediatric Bone Disease. His research focuses on treatment of ch ildhood bone fragility and rare bone diseases; basi c science group on early life events and skeletal development, as well as pathophysiology of childhood bone diseases.

Derek Burke (MBBS, FRC SEd, FRCEM, FRCPCH) is a professor, Consultant Paediatric Emergency Physician and Medical Director at Sheffield Children's NHS Foundation Trust.

Amaka Offiah (BSc, MBBS, MRCP, FRCR, PhD,

FRCPCH) is a professor in Paed iatric Musculoskeletal Imaging. Her research includes imaging of suspected child abuse and skeletal dysplasias and in methods of determining which children have fragile bones prone to fracture. 